\title{
A RESOLUÇÃO CNE/CP N. 2/2019 E OS RETROCESSOS NA FORMAÇÃO DE PROFESSORES
}

\author{
Resolution CNE/CP n.2/2019 and the retrocesses in teacher training \\ Resolución CNE/CP n. 2/2019 y los antecedentes en la formación de profesores \\ Suzane da Rocha Vieira Gonçalves * \\ Maria Renata Alonso Mota ** \\ Simone Barreto Anadon ***
}

https://doi.org/10.38117/2675-181X.formov2020.v2i2n4.360-379

\section{RESUMO}

Este artigo problematiza as Diretrizes Curriculares Nacionais (DCN) para Formação de Professores aprovadas pelo Conselho Nacional de Educação em dezembro de 2019. Por meio de uma análise preliminar da Resolução CNE/CP n. 2/2019, procura-se discutir os principais impactos desta para a formação de professores. Tomamos como ponto de partida a Resolução CNE/CP n. 2/2015, para identificar as mudanças que envolvem aspectos pedagógicos e políticos para a formação docente. A análise evidencia o alinhamento das atuais diretrizes com a Base Nacional Comum Curricular; a assunção da noção de competências para a construção dos currículos das licenciaturas; o silenciamento com relação às discussões da formação continuada e da valorização profissional; entre outros aspectos. Por fim, entende-se que as atuais DCN representam um retrocesso para a formação de professores, privilegiando uma formação tecnicista, padronizada e pragmática, que pode acarretar um crescente controle do ser e do fazer docente.

PALAVRAS CHAVE: Política Educacional; Formação de Professores; Diretrizes Curriculares Nacionais

\section{RESUMEN}

Este artículo analiza las Directrices Nacionales de Currículo (DCN) para la formación de docentes aprobadas por el Consejo Nacional de Educación en diciembre de 2019. A través de un análisis preliminar de la Resolución CNE/CP n. $2 / 2019$, buscamos discutir los principales impactos de esta para la capacitación docente. Tomamos la resolución CNE/CP n. 2/2015, para identificar los cambios que involucran aspectos pedagógicos y políticos para la formación del profesorado. El análisis muestra la alineación de las directrices actuales con la Base Curricular 
Nacional Común; la asunción de la noción de competencias para la construcción de planes de estudio de pregrado; el silencio sobre las discusiones de educación continua y desarrollo profesional; entre otros aspectos. Finalmente, se entiende que el DCN actual representa un revés para la formación del profesorado, privilegiando la formación técnica, estandarizada y pragmática, lo que puede conducir a un control creciente del ser y la enseñanza.

PALABRAS CLAVE: Políticas educativas; Formación del profesorado; Directrices Curriculares Nacionales.

\section{ABSTRACT}

This paper discusses the National Curriculum Guidelines (NCG) for Teacher Training approved by the National Education Council in December 2019. Through a preliminary analysis of Resolution CNE/CP n. 2/2019, we seek to discuss its main impacts for teacher education. We take Resolution CNE/CP n. 2/2015, to identify the changes that involve pedagogical and political aspects for teacher education. The analysis shows the alignment of the current guidelines with the National Curricular Common Core; the assumption of the notion of competencies for the construction of undergraduate curricula; the silence regarding the discussions of continuing education and professional development; among other aspects. Finally, it is understood that the current NCG represents a setback for teacher education, privileging a technical, standardized and pragmatic training, which can lead to an increasing control of being and making teachers.

KEYWORDS: Educational policies; Teacher training; National Curriculum Guidelines.

\section{Considerações Iniciais}

Esse trabalho problematiza questões relativas à política de formação de professores no Brasil, mais precisamente às Diretrizes Curriculares Nacionais para Formação de Professores aprovadas pelo Conselho Nacional de Educação em dezembro de 2019. A Resolução CNE/CP n. 2/2019, que instituiu as diretrizes, foi fortemente criticada por entidades acadêmicas e pela comunidade universitária, pela falta de discussão do seu conteúdo, e por apresentar um viés pragmático para formação docente. Segundo as críticas, trata-se de um retrocesso em relação às conquistas vinculadas ao conjunto de mudanças empreendidas pelas diretrizes anteriores (SILVA, 2020; BAZZO, SCHEIBE, 2019). 
É importante salientar que a formação de professores tem se tornado central no âmbito das políticas educacionais empreendidas desde a década de 1990. As reformas educativas no Brasil, desde esse período, objetivaram adequar o sistema educacional ao processo de reestruturação produtiva e aos novos rumos do Estado. Especialmente a partir do Governo de Fernando Henrique Cardoso, afirmou-se a centralidade da educação, dando-se grande peso à formação dos seus profissionais. Nesse contexto, diferentes propostas para a formação de professores e especialistas da educação, fundadas em projetos políticos e perspectivas históricas diferenciadas, colocam-se na cena e entram em disputa.

A década de 1990 foi marcada por intenso movimento de reformas políticas, que reconfiguraram a educação em todos os seus níveis, teve como um dos seus marcos a aprovação da Lei de Diretrizes e Bases da Educação Nacional em 1996. Observa-se que as reformulações realizadas internamente vieram articuladas a ajustes orientados por organismos internacionais a fim de cumprir acordos de contrapartida à tomada de empréstimos para esta área. Entre as reformas educacionais iniciadas na década de 1990, destacamos a da formação dos professores, que precisam ser compreendidas como parte das ações implementadas no contexto da reestruturação do Estado brasileiro que, em consonância com os preceitos da chamada "agenda neoliberal", promoveu ajustes, estabeleceu novos marcos regulatórios, mudando substancialmente o campo da educação.

Com a aprovação da Lei de Diretrizes e Bases da Educação Nacional - Lei n. 9.394/96, o Conselho Nacional de Educação - CNE foi impelido a elaborar diretrizes curriculares para os diferentes níveis e etapas educacionais. Nesse sentido, desde 1996 foram aprovadas três Diretrizes Curriculares Nacionais para a Formação de professores. Analisar e discutir a última delas é o que se busca fazer neste texto, apontando alguns desafios que estão postos para a Formação Docente, bem como discutir os principais impactos das diretrizes para a formação de professores. Cabe destacar, que no presente artigo são discutidos resultados preliminares, de uma pesquisa em andamento que busca a partir da metodologia da análise documental compreender as concepções presentes na Resolução CNE/CP n. 02/20219, bem como seus possíveis efeitos para a formação docente. A investigação vem sendo conduzida, a partir de aportes teóricos nacionais e internacionais acerca da formação do docente e das políticas públicas para a formação de professores.

\section{Formação de Professores e legislação: uma dinâmica relação}

Conforme anunciado na seção anterior, desde a aprovação da Lei de Diretrizes e Bases da Educação Nacional em 1996, o CNE publicou três Diretrizes para a Formação de Professores. A primeira DCN data de 2002, a segunda de 2015 e, a última foi publicada em 20 de dezembro de 2019. 
Em 2002, a Resolução CNE/CP n.1/2002, caracterizou-se por um texto enxuto, que estabelecia que as Diretrizes "constituem-se de um conjunto de princípios, fundamentos e procedimentos a serem observados na organização institucional e curricular de cada estabelecimento de ensino e aplicam-se a todas as etapas e modalidades da educação básica" (BRASIL, 2002). Seguindo as orientações da época, "o conceito de competências é apresentado como nuclear na organização curricular - um "novo" paradigma educacional" (DIAS, LOPES, 2003, p.1153).

A noção de competência, ainda que muito criticada no período por diversos pesquisadores (DIAS, LOPES, 2003; MAUÉS, 2004) foi assumida como orientadora para se pensar o currículo da formação docente. No ano seguinte à aprovação da Resolução CNE/CP n. 1/2002, assume a presidência da República Luiz Inácio Lula da Silva. Com a sua chegada no governo algumas políticas educacionais foram sendo reconfiguradas e a noção de competências acabou perdendo força no campo educacional.

Com as mudanças nas concepções presentes nas políticas educacionais, o Conselho Nacional de Educação foi pressionado para empreender uma revisão das Diretrizes Curriculares Nacionais para a Formação de Professores. Até a aprovação das Diretrizes em 2015, a comissão bicameral do CNE foi recomposta várias vezes. Neste contexto, é importante destacar que com a aprovação da Lei $n^{\circ}$ 13.005/2014 que instituiu o Plano Nacional de Educação - PNE pelo Congresso Nacional inaugura-se uma nova fase para as políticas educacionais brasileiras (DOURADO, 2015).

Assim, tendo como horizonte as Metas 12,15,16,17 e 18 do PNE nas estratégias que tratam da formação dos profissionais da Educação e sua valorização, CNE comissão bicameral partir de 2014,

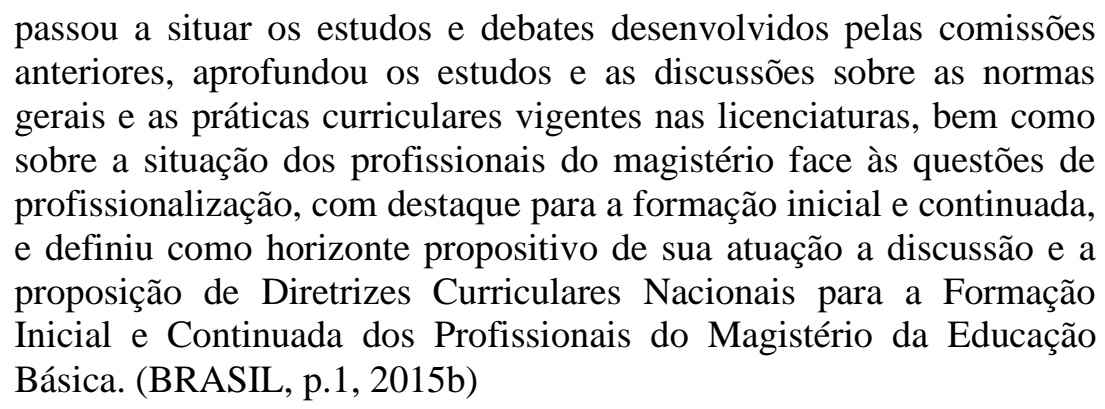

A partir deste período, a comissão desenvolveu o seu trabalho em consonância com vários movimentos da época que defendiam a formação de professores articulada com a valorização desses profissionais. Desse modo, o Conselho Nacional de Educação buscou, a partir da proposição de uma nova Resolução para a Formação de Professores, dar maior organicidade para a formação de profissionais do magistério da Educação Básica, incluindo a rediscussão das Diretrizes e outros instrumentos normativos acerca 
A Resolução CNE/CP N. 2/2019 e os retrocessos na formação de professores

da formação inicial e continuada. Esse processo agregou, também, a discussão de aspectos relacionados à valorização dos profissionais da educação (DOURADO, 2015).

Após um grande debate e múltiplas articulações, foram aprovadas em 2015 as Diretrizes Curriculares Nacionais para a formação inicial em nível superior (cursos de licenciatura, cursos de formação pedagógica para graduados e cursos de segunda licenciatura) e para a formação continuada. Pela primeira vez na história, tinha-se um documento orgânico que ousava articular a formação inicial e continuada envolvendo as universidades e a Educação Básica. A Resolução CNE/CP n. 2/2015 foi recebida no meio acadêmico como uma grande conquista da área da educação, uma vez que buscou contemplar em seu texto concepções historicamente defendidas por entidades da área, como Associação Nacional pela Formação dos Profissionais da Educação - ANFOPE, Associação Nacional de Política e Administração da Educação - ANPAE, Associação Nacional de Pós-graduação e Pesquisa em Educação - ANPED, Centro de Estudos Educação e Sociedade - Cedes e Fórum Nacional de Diretores de Faculdades, Centros de Educação ou Equivalentes das Universidades Públicas Brasileiras - FORUMDIR. Isto foi possível, por ter sido um documento construído a partir de um amplo debate realizado com as entidades acadêmicas, universidades, sindicatos, e professores da Educação Básica.

Importante dizer que a Resolução CNE/CP n. 2/2015, é composta por vinte e cinco artigos e oito capítulos que procuram dar conta da formação inicial, da formação continuada e da valorização dos profissionais do magistério. Entre as principais proposições da Resolução CNE/CP n. 2/2015 estão a ampliação da carga horária para os cursos de formação inicial para 3.200 horas, a indicação da elaboração de um projeto institucional de formação de professores por partes das instituições formadoras, a indicação da base comum nacional, pautada pela concepção de educação como processo emancipatório e permanente, bem como pelo reconhecimento da especificidade do trabalho docente, que conduz à práxis como expressão da articulação entre teoria e prática e à exigência de que se leve em conta a realidade dos ambientes das instituições educativas da educação básica e da profissão, a definição de que os cursos de formação inicial para os profissionais do magistério para a educação básica, em nível superior, compreendem: cursos de graduação de licenciatura; cursos de formação pedagógica para graduados não licenciados; e cursos de segunda licenciatura. Ainda destacamos que a resolução estabelece que os cursos de formação inicial deverão ser organizados em três núcleos, o primeiro de estudos de formação geral, o segundo de aprofundamento e diversificação de estudos das áreas de atuação profissional e o terceiro núcleo de estudos integradores para enriquecimento curricular (BRASIL, 2015).

A Resolução CNE/CP n. 2/2015 ainda dedica todo o Capítulo VI para tratar da Formação Continuada dos Profissionais do Magistério, discutindo os aspectos que devem ser contemplados nos cursos, programas e ações de formação continuada e ainda 
estabelece quais atividades podem ser consideradas como de formação continuada (BRASIL, 2015). E apresenta o capítulo VII para tratar da política de valorização dos profissionais do magistério da Educação Básica, aspecto considerado uma grande inovação em termos de diretrizes e uma conquista histórica para todos profissionais da educação.

Observa-se que a partir das proposições presentes na Diretriz de 2015, a proposta curricular para a formação de professores rompe com a lógica das competências presente no conjunto de diretrizes pós LDB e que marcaram as discussões curriculares no final da década de 1990 e início dos anos 2000. Trouxeram para o debate da formação de professores temas caros à profissão docente, como as questões pedagógicas, a gestão educacional e as temáticas que envolvem a diversidade de sujeitos, culturas e saberes no contexto escolar.

A Resolução CNE/CP n. 2/2015 teve seu prazo de implementação prorrogado por três ${ }^{1}$ vezes, essas prorrogações e a troca do governo desmobilizaram algumas instituições na discussão dos seus currículos e na elaboração das novas propostas curriculares a luz da nova legislação. $\mathrm{O}$ fantasma da revogação destas diretrizes passou a rondar o cenário político educacional. Este período foi marcado, também, por mudanças nos membros do CNE, como anunciam Bazzo e Scheibe,

No processo de troca de orientação política em todas as esferas do poder, no pós-Golpe, a referida legislação, elaborada, discutida e aprovada pelo Conselho Nacional de Educação, cujos membros mais progressistas foram, nesse novo momento, substituídos, teve sua implantação inicialmente atravessada por tentativas oficiais de procrastinação. Foi a pronta reação das entidades representativas dos educadores que impediu tal iniciativa de prosperar imediatamente. $(2019$, p. 671)

O novo direcionamento da política educacional, de viés privatista e pouco dialógico, do pós-golpe de 2016 que destituiu a presidenta Dilma Rousseff, deu "continuidade" em políticas como a Base Nacional Comum Curricular - BNCC, redirecionando concepções educacionais. Parte do grupo que esteve no Ministério da Educação na década de 1990 e que tinha a noção de competências como eixo curricular, retorna ao governo em 2016, no âmbito do MEC e do CNE resgatando tais concepções.

Com a aprovação da BNCC em 2017, tanto o Ministério da Educação como o Conselho Nacional de Educação acentuaram o discurso da necessidade de revisão das diretrizes de formação de professores. As universidades e entidades educacionais reiteraram o discurso e a defesa pela manutenção da Resolução CNE/CP n. 2/2015,

\footnotetext{
1 Conforme as Resoluções: Resolução CNE/CP n ${ }^{\circ} 1$, de 9 de agosto de 2017; Resolução CNE/CP nº 3 , de 3 de outubro de 2018 e Resolução CNE/CP n 1 , de 2 de julho de 2019.
} 
alegando que seu conteúdo permitia a adequação dos currículos à $\mathrm{BNCC}$, sem a necessidade de extingui-la. Também argumentavam, que os cursos já adequados às DCNs de 2015, não haviam encerrado um ciclo, portanto não se tinha ainda uma avaliação do desempenho das diretrizes curriculares na formação dos professores.

Mesmo com todos os apelos e manifestações de entidades como ANFOPE, ANPAE, ANPED, CEDES, FORUMDIR, Confederação Nacional dos Trabalhadores da Educação - CNTE e do Colégio de Pró-reitores de Graduação das Instituições Federais de Ensino Superior - COGRAD, pela manutenção da Resolução CNE/CP n. 2/2015, o Ministério da Educação encaminhou para o Conselho Nacional de Educação a Proposta para Base Nacional Comum da Formação de Professores da Educação Básica, em dezembro de 2018, no apagar das luzes do governo Temer.

A Proposta de Base Nacional Curricular para a Formação de Professores encaminhada pelo MEC ao CNE não foi discutia com as universidades, professores da Educação Básica e entidades educacionais. Tratava-se de um texto, elaborado por um grupo de consultores vinculados a empresas e assessorias educacionais privadas. $\mathrm{O}$ documento resgata a noção de competências como orientadora da formação de professores e baseia-se no modelo de base utilizado pela Austrália para a formação docente. O modelo Australiano, implementado desde 2009, incorpora as propostas neoliberais de maior controle sobre o trabalho docente com vistas no desempenho no PISA (Australian Professional Standards for Teachers, 2018).

Depois de chegar no CNE o texto não foi divulgado, e apenas em setembro de 2019, após pressão das entidades educacionais, o conselho agendou uma audiência pública, com vagas limitadas, para novembro de 2019. A maioria dos presentes na audiência, manifestaram-se contrários à revogação das Diretrizes Curriculares Nacionais aprovadas em 2015, as manifestações da ANFOPE, ANPED e FORUMDIR solicitaram a manutenção da Resolução CNE/CP n. 2/2015 tendo em vista os avanços presentes na proposta de um documento que pensa, discute e propõe a formação de professores de modo orgânico e a necessidade de se avaliar os efeitos da diretrizes junto às Instituições Formadoras. Mas, ainda assim, o CNE aprovou em novembro de 2019 a proposta de uma nova diretriz curricular e a revogação da DCN de 2015. A nova diretrizes, instituída pela Resolução CNE/CP n. 2/2019 só foi homologada pelo Ministério da Educação em 20 em dezembro de 2019.

As novas Diretrizes Curriculares Nacionais para a Formação de Professores rompem drasticamente com conquistas históricas para a formação e valorização profissional docente expressas na Resolução CNE/CP n. 2/2015. A Resolução CNE/CP n. 2/2019 é um documento que possui inconsistências, entra em conflito com as Diretrizes Curriculares Nacionais do Curso de Pedagogia, busca uma formação pragmática e padronizada, pautada na pedagogia das competências e comprometida com os interesses 
mercantilistas de fundações privadas. Dias e Lopes (2003), ao analisarem as reformas educacionais no Brasil na década de 1990, afirmam que o conceito de competências é recontextualizado de programas americanos para formação de professores no Brasil. Segundo as autoras, é através desse conceito recontextualizado que se articula a estreita relação entre educação e mercado. Observamos que o mesmo fenômeno que as autoras apontavam no contexto da Resolução de 2002 acerca da formação docente, é retomado no atual momento histórico na Resolução de 2019.

Nas palavras da ANFOPE, "as 'novas' Diretrizes Nacionais Curriculares e a BNC da Formação descaracterizam os cursos de licenciatura e empobrecem a qualidade da formação de professores. Para a entidade, pode se inferir impactos nocivos sobre a educação básica, que constituem mais um grave retrocesso nas políticas educacionais" (ANFOPE, 2020).

A Resolução CNE/CP n. 2/2019, possui trinta artigos, organizados em nove capítulos e um anexo que apresenta a proposta da Base Nacional Comum para a Formação Inicial de Professores da Educação Básica (BNC-FORMAÇÃO). As novas Diretrizes, publicadas em 2019, evidenciam o total alinhamento com a Base Nacional Comum Curricular da Educação Básica. Em mais de um momento é ressaltada a necessidade da formação docente seguir os princípios das competências gerais da BNCC.

Importante dizer que a Resolução CNE/CP n. 2/2019 trata exclusivamente da formação inicial de professores, ainda que brevemente citada ao longo do texto, em apenas três incisos, a formação continuada deixa de ser um tema da presente diretriz. Segundo o CNE, a formação continuada terá uma resolução específica. Tal mudança, rompe com organicidade que se buscou constituir com a Resolução CNE/CP n. 2/2015 e certamente trará prejuízos para a necessária articulação entre a formação inicial e continuada e entre universidade e as escolas da Educação Básica. Da mesma forma, a valorização profissional que possuía um capítulo na Resolução de 2015, fica reduzida em um inciso no texto atual.

A partir da nova diretriz, a formação inicial de professores deixa de estar organizada por núcleos e passa a ter sua organização a partir de três dimensões, quais sejam: I - conhecimento profissional; II - prática profissional; e III - engajamento profissional. Para cada dimensão são estabelecidas competências. Cada uma, destas dimensões, estão estruturadas a partir de competências específicas e para cada uma das competências específicas são listadas habilidades. Cabe dizer que as dimensões propostas para a organização da formação docente no Brasil são idênticas às dimensões estabelecidas na proposta curricular australiana (AUSTRÁLIA, 2018).

No que se refere a carga-horária dos cursos de licenciatura, a nova resolução mantém as 3200 horas. Todavia, estabelece que este cômputo de horas precisa estar 
organizado em três grupos. O Grupo I com 800 horas que precisam ser efetivadas desde o início no $1^{\circ}$ ano do curso. Neste grupo devem ser trabalhados aspectos referentes à base comum que compreende os conhecimentos científicos, educacionais e pedagógicos e fundamentam a educação e suas articulações com os sistemas, as escolas e as práticas educacionais. O Grupo II com 1.600 horas que devem ser cumpridas a partir do segundo ano do curso até o quarto ano. Nessa etapa formativa deve ser trabalhada a aprendizagem dos conteúdos específicos das áreas, componentes, unidades temáticas e objetos de conhecimento da BNCC, e para o domínio pedagógico desses conteúdos. E por fim, o Grupo III com 800 horas que devem ser desenvolvidas desde o primeiro ano do curso e que configuram a prática pedagógica no currículo. Este quantitativo de horas práticas deve ser distribuído em 400 horas para o estágio supervisionado, em situação real de trabalho na escola e 400 horas para a prática dos componentes curriculares dos Grupos I e II, distribuídas ao longo do curso, desde o início.

A nova Resolução, caracteriza-se por um modo prescritivo acerca de como deve ser a formação inicial de docentes no país. Ao estabelecer a forma como a carga horária deve ser distribuída, não apenas em termos de horas, mas também em conteúdos e anos do currículo, acaba por padronizar e engessar os cursos de formação de professores. A organização descrita em detalhes limita a autonomia das universidades na organização curricular dos cursos. Cabe destacar, que as atividades complementares, presentes desde 2002 como componente curricular dos cursos de licenciatura, desaparecem das atuais DCNs.

Outra mudança que se observa, diz respeito à formação em segunda licenciatura. A Resolução de 2015, estabelecia a carga-horária conforme a formação original e a nova licenciatura a ser cursada. Sendo assim, os cursos teriam uma carga horária mínima variável de 800 a 1.200 horas, sendo a carga horária do estágio curricular supervisionado estabelecida em 300 horas. A nova Resolução estabelece uma carga horária única de 1.120 horas independente da formação inicial e a nova licenciatura pretendida. A carga horária estabelecida deverá também ser organizada em três grupos. Das 1.120 horas, 200 horas que compõem o Grupo III são destinadas para a prática pedagógica na área ou no componente curricular. Evidencia-se, neste ponto, uma redução do tempo da experiência do exercício da docência, ao mesmo tempo que não menciona a obrigatoriedade do estágio, e sim, de práticas.

É importante ainda mencionar que a nova Resolução aponta mudanças significativas para a formação de professores para Educação Infantil, anos iniciais do Ensino Fundamental e Gestão Educacional. A formação destes profissionais tem sido realizada historicamente nos cursos de Pedagogia, o qual possui diretrizes curriculares próprias (Resolução $\mathrm{CNE} / \mathrm{CP}$ n. 1/2006) e que estabelecem que não deve haver habilitações para a formação do pedagogo, que possui a docência como base de sua formação. No entanto, a Resolução CNE/CP n. 2/2019 no capítulo que trata dos Cursos 
de Licenciatura, não menciona os cursos de Pedagogia e faz referência ao "curso de formação de professores multidisciplinares da Educação Infantil" e ao "curso de formação de professores multidisciplinares dos anos iniciais do Ensino Fundamental". Até a aprovação da presente resolução não se utilizava estes termos para se referir à formação destes docentes.

No que se refere à Gestão Educacional, a Resolução CNE/CP n. 2/2019, destina um capítulo específico para tal formação. Estabelece no artigo 22 que esta formação deve ocorrer nos cursos de Pedagogia, com aprofundamento de estudos nas áreas de gestão de 400 horas, ou seja, os cursos de Pedagogia deverão ter a carga horária mínima de 3.600 horas. Ainda estabelece que para o exercício profissional das funções relativas a essas áreas, a experiência docente é pré-requisito.

Por fim, considera-se necessário destacar que a Resolução destina um capítulo para tratar de Processo Avaliativo Interno e Externo. Neste capítulo, indica inclusive que o Instituto Nacional de Estudos e Pesquisas Educacionais - INEP deverá elaborar um novo instrumento de avaliação, em um prazo de dois anos em novo formato avaliativo para as licenciaturas. Aqui destacam-se dois aspectos, o primeiro é uma Resolução do CNE que trata do currículo dos cursos de formação de professores estabelecer ações para o INEP, o qual já é responsável pelos processos de avaliação dos cursos de graduação. O outro aspecto, diz respeito a tendência assumida nas atuais Diretrizes de padronizar o currículo para ter parâmetros para avaliar, assim o que está a luz da nova proposta curricular não é a qualificação da formação docente, mas a avaliação.

\section{Formar professores no contexto das Diretrizes de 2019}

A partir do que foi exposto na seção anterior apresenta-se algumas análises preliminares da Resolução CNE/CP n. 02/2019, tendo como foco a formação de professores nos cursos de licenciatura. Procura-se abordar dois aspectos que permeiam a perspectiva de formação inicial de professores apresentada nesta Resolução, a saber: o alinhamento da DCN com a formação de competências da BNCC; e a centralidade em processos formativos pautados em modelo técnico instrumental e prescritivo. Ainda que estes aspectos sejam abordados separadamente neste texto, eles estão imbricados e compõem princípios para a formação de professores que fazem desta DCN uma estratégia potente para o alinhamento das atuais políticas educacionais com a racionalidade neoliberal.

No que diz respeito ao primeiro aspecto a ser abordado, chama a atenção o alinhamento das Diretrizes de 2019 com a BNCC no que diz respeito a formação de competências. Esse direcionamento é explicitado desde o capítulo 1 da Resolução, que trata do Objeto. $\mathrm{O}$ Art. $2^{\circ}$, define que a formação docente pressupõe que o licenciando 
desenvolva as competências gerais previstas na BNCC-Educação Básica, sendo que estas, conforme apresenta o Art. $3^{\circ}$, servirão de base para o desenvolvimento de competências gerais docentes. As competências gerais e as específicas, agregadas de suas correspondentes habilidades são os aspectos que compõem a Base Nacional Comum para a Formação Inicial de Professores da Educação Básica (BRASIL, 2019). Cabe ressaltar conforme já destacado na seção anterior, que no âmbito deste capítulo da Resolução, as competências profissionais dos docentes estão delimitadas por três dimensões: conhecimento profissional; prática profissional; e engajamento profissional.

A ênfase nas competências revela o alinhamento da DCNs de formação de professores com a BNCC. Toda a Resolução aponta para a formação de professores tem como foco principal, saber desenvolver em seus futuros alunos, desde a Educação Infantil até o Ensino Médio, as competências e as habilidades definidas na BNCC. Pode-se depreender disso, que o trabalho do futuro professor será basicamente o de traduzir e ter os atributos necessários para colocar em prática o que já está definido na BNCC. Ademais, ao analisar as competências indicadas na BNC-Formação estas estão centradas no saber fazer. Temos aí, um direcionamento para a formação de professores da Educação Básica que está pautado em um modelo padronizado de desenvolvimento de competências e habilidades.

Nesse sentido, as Diretrizes de 2019 representam um movimento de padronização dos processos de formação de professores, incidindo fortemente em como o saber deve ser administrado em detalhes, de forma a produzir currículos mínimos que estão pautados em competências e habilidades. Sobre as competências no campo da educação, Masschelein e Simons (2013, p.90), afirmam que o problema não reside nas competências em si mesmas, mas

o problema surge quando as transformamos no objetivo fundamental da escola - como muitas vezes acontece - e quando começam a funcionar como resultados de aprendizagem que devem ser produzidos como produtos; em resumo, quando a aprendizagem (competências) toma $\mathrm{o}$ lugar do estudo e da prática. A medida que as competências (profissionais) ditarem o que é importante no mundo de hoje, o desafio, realmente, se situa na busca por matéria adequada. A matéria é o que é tratado na escola - e não perfis e competências.

Com um processo de padronização e unificação, são eleitas algumas questões que passam a ser prioritárias e outras ficam de fora. O que observamos com a Resolução CNE/CP n. 2/2019 é que o que passa a ser prioritário neste momento são as competências e habilidades. Como afirmam Albino e Silva (2019, p. 141), os modelos curriculares por competência preocupam "por consubstanciar em uma perspectiva reducionista do conhecimento a esquemas e modelos, em detrimento de um modelo processual de compreensão curricular". E ao privilegiar tal perspectiva para a proposição de diretrizes para a formação inicial de professores, alguns aspectos muito relevantes e que 
representavam conquistas para o campo educacional ficaram relegados a um segundo plano.

Uma das questões que ficou relegada a um segundo plano é o Projeto Institucional de Formação de Professores instituído pela Resolução CNE/CP n. 2/2015 e que desaparece com a Resolução CNE/CP n. 2/2019. A proposição deste Projeto Institucional forjava uma forte articulação entre a formação inicial e continuada de professores da Educação Básica e aproximava universidades e escolas.

Cabe ressaltar que este processo de construção dos projetos institucionais que foi vivenciado nas instituições de Ensino Superior brasileiras, resultou em um processo de discussão produtiva, que teve efeitos nos currículos dos cursos de licenciatura, bem como nas relações estabelecidas com a Educação Básica. Esse modo processual de compreensão curricular da formação de professores, destacado por Albino e Silva (2019), parece não ser mais priorizado. Dizemos isso, porque a imposição de diretrizes padronizadas e pautadas em modelos de currículo mínimo, desconsideram os processos que estavam sendo construídos em cada instituição de ensino superior, em um diálogo que envolveu professores das diferentes licenciaturas, Secretarias de Educação e escolas da Educação Básica.

Esse aspecto tem relação com o segundo ponto que se quer problematizar no âmbito desta seção do artigo. A formação com ênfase nas competências e habilidades está ligada, também, à centralidade em processos formativos pautados em um modelo técnico instrumental e prescritivo.

As competências específicas presentes na Resolução CNE/CP n. 2/2019, elencadas nas três dimensões - conhecimento profissional, prática profissional e engajamento profissional -, evidenciam este modelo técnico instrumental. Dentre as competências para cada uma destas dimensões, elencadas nos parágrafos $1^{\circ}, 2^{\circ}$ e $3^{\circ}$ do Art. $4^{\circ}$, destacamos as seguintes ações:

dominar os objetos de conhecimento e saber como ensiná-los; demonstrar conhecimento sobre os estudantes e como eles aprendem; reconhecer os contextos de vida dos estudantes; conhecer a estrutura e a governança dos sistemas educacionais; planejar as ações de ensino que resultem em efetivas aprendizagens; criar e saber gerir os ambientes de aprendizagem; avaliar o desenvolvimento do educando, a aprendizagem e o ensino; conduzir as práticas pedagógicas dos objetos do conhecimento, as competências e as habilidades; comprometer-se com o próprio desenvolvimento profissional; engajar-se, profissionalmente, com as famílias e com a comunidade, visando melhorar o ambiente escolar (BRASIL, 2019, p. 02).

Ao analisar as ações que compõem as competências de cada dimensão, percebese uma forte ênfase em aspectos que mostram o quanto a formação de professores da Educação Básica está pautada na centralidade da prática. Não há qualquer ação que 
priorize ou encaminhe a reflexão acerca do campo educacional ou dos processos educativos. Nas habilidades definidas para cada dimensão, que são apresentadas na BNCFormação encontra-se poucas que mencionam alguma ênfase no exercício reflexivo e criativo. Estas, estão localizadas na dimensão do engajamento profissional e, por serem em número bastante restrito, acabam por não ganhar grande visibilidade no âmbito desta Resolução. O saber fazer ganha prioridade frente aos processos analíticos do contexto e da realidade educacional em suas diferentes etapas. Este aspecto parece ser de grande relevância, pois entende-se que os processos reflexivos e de criação estão intimamente imbricados com a docência.

A centralidade em processos formativos pautados em um modelo técnico instrumental e prescritivo é evidenciada, também, no capítulo IV das Diretrizes de 2019, que trata dos cursos de licenciatura. No Art. 11 deste capítulo, que aborda a distribuição da carga horária dos cursos de formação de professores, e também nos artigos subsequentes, que define as 800 horas para a base comum com os conhecimentos científicos, educacionais e pedagógicos e as 1.600 horas, compreendendo os conteúdos específicos das áreas, e da BNCC, há um detalhamento minucioso que prioritariamente privilegia de forma prescritiva a instrumentalização técnica. Com isso, tem-se uma visão estreita de currículo de formação docente, que prioriza a padronização, com efeitos de um controle excessivo frente aos projetos pedagógicos e dos currículos dos cursos, bem como do trabalho docente.

As análises preliminares aqui problematizadas, apontam para diretrizes que apresentam um currículo mínimo nacional padronizado, que relega a segundo plano a formação teórica e os conhecimentos do campo das ciências humanas. A Resolução CNE/CP n. 2/2019 aponta para um currículo de formação "perspectivado em um modelo de organização corporativa para atender ao mercado em que as ciências humanas são suprimidas/marginalizadas, no rol de saberes 'importantes'. A boa formação parece apontar para aquela que o sujeito 'sabe fazer"” (ALBINO e SILVA, 2019, p. 150).

Este direcionamento apontado pelas Diretrizes de 2019, vai na contramão da ideia de base comum nacional defendida pela ANFOPE, que se constitui de princípios orientadores que devem estar presentes nos processos formativos dos cursos de licenciatura, dentre eles: uma sólida formação teórica e interdisciplinar no campo da educação; a unidade entre teoria e prática; compromisso social, político e ético com um projeto comprometido com a transformação das relações sociais; caráter problematizador do trabalho educativo.

A partir do que foi abordado até aqui, pode-se afirmar que a Resolução CNE/CP n. 2/2019 vem se configurando como estratégia potente para a materialização da reforma curricular da Educação Básica em curso nas atuais políticas públicas educacionais no Brasil e que têm forte alinhamento com a racionalidade neoliberal. Ela forma um fio 
condutor que amarra e articula formação de professores e Educação Básica, conectadas e fundamentadas nas competências e habilidades definidas na BNCC.

Abre-se, a partir de tal proposição, uma porta considerável para o mercado, que estará apto a fornecer produtos e serviços no âmbito educativo alinhados a missão de concretizar a BNCC nas salas de aula do país. A Resolução CNE/CP n. 2/2019 configurase como estratégia potente, que se articula com outros arranjos, de forma a compor uma rede de formação de capital humano atrelada aos princípios do neoliberalismo em uma versão conservadora.

\section{Docência no Ensino Superior e formação de professores no contexto da nova legislação}

A Resolução CNE/CP n. 2/2015 abria o diálogo em meio aos cursos de licenciatura para que os docentes formadores, pudessem adentrar o debate acerca da formação de licenciandos considerando um fazer complexo, peculiar e que envolve uma amálgama de conhecimentos advindos de diferentes fontes. Corroborando ainda com o diálogo, o documento propunha a aproximação das universidades com as redes de ensino configurando um processo contínuo de formação que empreendia a tessitura necessária entre as práticas de formação inicial e continuada.

Segundo a Resolução CNE/CP n. 2/2015 o exercício do magistério configura ações que envolvem intencionalidade e metodologia e que demandam conhecimentos advindos de diferentes campos disciplinares em contínuo diálogo. $\mathrm{O}$ documento afirma as diferentes dimensões da formação e da atividade docente, a saber, um aporte científico consistente, um repertório cultural amplo, um domínio dos valores "éticos, linguísticos, estéticos e políticos do conhecimento" (BRASIL, 2015, p.03). Tal concepção acerca da docência remete à produção do campo científico da formação de professores que compreende, como definido por Cunha (2010), o fazer docente como "requerente de múltiplas condições para seu exercício" (p.23). Dentre uma das principais condições a de uma sólida formação teórica e prática. Um processo formativo que assuma o ato pedagógico em sua complexidade e no bojo de implicações culturais e políticas.

Desde dezembro de 2019 tem-se novas Diretrizes para a Formação de Professores

e uma Base Nacional Curricular para a Formação de Professores. É a primeira vez que se tem de forma tão definida a abordagem para o trabalho com a formação de docentes no Brasil. O documento é prescritivo, e conforme já abordado nas seções anteriores, configura uma perspectiva pedagógica ancorada em pressupostos do saber fazer, do fazer didático como um conjunto de técnicas. Uma formação profissional resumida no desenvolvimento de competências e habilidades. Nesse sentido, desaparece do horizonte 
formativo a constituição de um professor com capacidades críticas, analíticas, reflexivas e criativas.

A nova Resolução, como já afirmado, tem centralidade na prática como premissa de uma formação de qualidade. Ainda que essa seja uma demanda histórica, e que anteriormente também tenha sido pauta das mudanças na Resolução CNE/CP n. 2/2015, no documento em vigor, a prática está posta como o saber fazer, como o domínio do conteúdo a ser desenvolvido e da melhor metodologia para tal, como um rol de competências e habilidades encerradas em si mesmas. Não há qualquer menção de prática como o diálogo entre esta e a teoria, entre esta e o questionamento dos conteúdos historicamente produzidos. O que se pode inferir dado o alinhamento da DCNs com a BNCC é que a prática é entendida como a aplicação dos conteúdos descritos pela Base.

Vários autores do campo da docência têm enfatizado que o desempenho profissional no magistério guarda especificidades e peculiaridades que demandam uma formação que reitere o compromisso com o diverso, com o local, com as individualidades, com as coletividades. Trata-se de um fazer marcado pela relação humana, e, por isso, a formação profissional, como argumenta Cunha (2010, p. 25) precisa considerar:

A docência como atividade complexa, exige tanto uma preparação cuidadosa como singulares condições de exercício, o que pode distingui-la de algumas outras profissões. Ou seja, ser professor não é tarefa para neófitos, pois a multiplicidade de saberes e conhecimentos que estão em jogo na sua formação, exigem uma dimensão de totalidade, que se distancia da lógica das especialidades, tão caras a muitas outras profissões, na organização taylorista do mundo do trabalho. [...] Se esse modelo serve para algumas profissões, distancia-se, certamente, da docência e das atividades profissionais dos educadores, pois a complexidade da docência não abre mão da dimensão da totalidade. Mesmo que seja factível a dedicação a um determinado campo de conhecimento, o exercício da docência exige múltiplos saberes que precisam ser apropriados e compreendidos em suas relações. A ciência pedagógica situa-se nesse contexto e só com essa perspectiva contribui para a formação de professores.

O que se pode inferir nesse momento é que no interior de cada instituição de Ensino Superior se instaure dúvidas e questionamentos acerca dos processos de formação de professores que apontam para o controle cada vez maior do trabalho dos docentes desse nível de educação. Afinal, a nova legislação prevê avaliações de dois em dois anos dos cursos e dos formandos das licenciaturas de modo a identificar se as DCNs vêm sendo atendidas. Estabelece-se assim, um enorme controle sobre a prática do professor formador nos cursos de formação docente, uma vez que, terão que desenvolver os conteúdos previstos na BNC-Formação, de modo que seus licenciandos possam obter sucesso no 
ENADE e, assim, manter os cursos em funcionamento e conceder aos estudantes o direito de atuar profissionalmente.

Pode-se considerar ainda, o impacto desta nova perspectiva no ser e fazer dos docentes do Ensino Superior. Mais do que produzir conhecimentos sobre ser professor, sobre o caráter político e pedagógico do exercício da docência, a preocupação dos docentes estará centrada na obtenção das credenciais necessárias ao funcionamento do curso de licenciatura ao qual está vinculado. Para além dos requisitos de produtividade no campo da pesquisa, o ensino trará esse novo cenário de fiscalização do fazer docente na universidade.

O que emerge de mais significativo no alinhamento entre as DCNs, a BNCFormação e a BNCC, é o controle do trabalho docente. A cada etapa da educação a qualidade do processo de ensino estará vinculada à métrica de testes padronizados. Professores terão de responder positivamente às demandas da legislação que poderá ser "conferida" pelo nível de sucesso dos educandos nas avaliações.

A imposição da noção de competências e de avaliações padronizadas em toda Educação Básica e no currículo das Licenciaturas tem como objetivo reorganizar o processo educacional brasileiro de forma a fazê-lo mais preciso e mensurável, logo administrável. São os parâmetros estabelecidos nesses dois expedientes - bases curriculares e avaliações - que definirão o comportamento de professores e estudantes. Impresso nessa dinâmica está o controle sobre os conhecimentos que devem ser trabalhados, tanto a forma como devem ser acessados quanto os períodos mais adequados para tal apropriação.

Para Freitas (2012), essas nuances estão associadas à perspectiva tecnicista que revisitada pelos pressupostos neoliberais alia às concepções comportamentalistas da Psicologia premissas gerencialistas e privatistas. Segundo o autor, o denominado neotecnicismo ancora-se em "três categorias responsabilização, meritocracia e privatização" (p.383).

O autor enfatiza que a tônica neotecnicista na educação, refere-se a um processo que busca responsabilizar os professores única e exclusivamente pelo desempenho dos estudantes nas avaliações. Caberá aos docentes prepará-los para um bom desempenho já que o reconhecimento das melhores instituições, assim como os incentivos e recursos às mesmas, estarão vinculados à classificação nos rankings nacionais. Dessa forma, responsabiliza os docentes pelo sucesso da educação no país.

O aspecto meritocrático, segundo Freitas (2012), está diretamente associado à responsabilização, uma vez que alunos e professores deverão ser reconhecidos em seus esforços, e valorizados a partir do desempenho demonstrado. A competição entre os pares 
e a percepção de que o bom desempenho é que pode comprovar mérito para receber investimentos e compensações se estabelece nas relações escolares e acadêmicas.

Por fim, as duas primeiras categorias estão diretamente vinculadas a privatização. Para o autor o ranking de desempenho das instituições educativas pode ser o sinalizador necessário para apontar novas perspectivas de gestão. A denominada gestão por concessão emerge após a constatação de que os sujeitos de uma determinada escola ou universidade não têm "competências" suficientes para administrá-la, o que abre a possibilidade de privatização da gestão. Ainda que a instituição educacional possa continuar de caráter público, a gestão é privatizada.

A implementação das novas Diretrizes Curriculares Nacionais para a Formação de Professores revela o avanço de uma perspectiva política que procura empreender práticas comprometidas com o empresariamento da educação. Estão em jogo interesses mercantilistas que percebem na educação um mercado em contínua expansão. A partir de novas diretrizes e base para a formação de professores, alinhadas com a BNCC e com as políticas de avaliação externa, desenham-se inúmeras possibilidades de produção de materiais didáticos, de promoção de formação inicial e continuada a serem ofertados pela iniciativa privada. Caberá aos docentes formadores encontrar espaços-tempos formativos que possam sinalizar tais movimentos, estabelecendo a crítica necessária e potencializando outros aspectos da formação de professores.

\section{Considerações finais}

Finalizando, entende-se importante enfatizar que o prazo para a atualização dos currículos para atender a Resolução CNE/CP n. 2/2015, ainda não havia se extinguido. Dessa forma, depreende-se que sequer houve tempo para que uma avaliação acerca do impacto das mudanças nos cursos de licenciatura pudesse ser empreendida de modo a apontar os avanços e as lacunas verificadas quando de sua implementação.

Não houve, assim, uma apreciação das transformações ocorridas que pudessem justificar a revogação de uma Resolução por outra, no que diz respeito a primar pela qualidade do ensino. O que se pode perceber é a imposição de uma perspectiva de formação de professores vinculada a interesses políticos neoliberais e conservadores, que vêm, nas novas Diretrizes a oportunidade de controlar o trabalho docente, de expandir seus ganhos com a oferta de cursos, com a produção de material didático e de livros que enfocam a prática pedagógica como a aplicação de métodos para desenvolver os conteúdos da BNCC.

A implementação da Resolução CNE/CP n. 2/2019, desconsiderou o movimento de alterações curriculares nos cursos de licenciatura em todas as universidades do país, 
demonstrando o descompasso entre os propositores das políticas e as instituições de ensino. Ao definir novas Diretrizes Curriculares Nacionais para a Formação de Professores sem discutir com a sociedade, o atual governo, nega as experiências, o escopo de estudos e pesquisas produzidos pelo coletivo de educadores no campo da formação de professores. Tal postura fortalece a perspectiva de um núcleo de poder que determina o conhecimento válido para a formação docente, qual seja, um saber prático, ancorado em pressupostos neotecnicistas.

É importante ressaltar que as universidades que avançaram no atendimento da Resolução CNE/CP n.2/2015, tinham construído o seu Projeto Institucional de Formação Inicial e Continuada de Professores da Educação Básica. $\mathrm{O}$ documento que atendia às diretrizes nacionais em consonância com as peculiaridades locais e com as trajetórias institucionais no campo da formação de professores consolidava a identidade de cada universidade em termos de formação de professores e significava um avanço importante para as licenciaturas. O Projeto Institucional de cada universidade, nesse momento, fica subsumido na nova legislação que parece desconsiderar não apenas o processo de construção coletiva empreendido, mas também, qualquer história institucional anterior no campo da formação docente.

Destaca-se, ainda, a ausência de direcionamentos nacionais para a formação continuada e para a valorização profissional de professores na referida legislação. Presentes na Resolução CNE/CP n. 2/2015, a formação continuada era percebida como um espaço a ser construído na parceria entre as escolas e as universidades, em um claro vínculo em que se reconhecia a instituição escolar como lugar de produção de conhecimentos. Nas DCNs em vigor, não há menção sobre essa relação, ou mesmo sobre o papel de gestores, instituições ou sujeitos nesse processo.

\section{Referências}

ALBINO, Ângela Cristina Alves e SILVA, Andréia Ferreira da. BNCC e BNC da formação de professores: repensando a formação por competências. In: Revista Retratos da Escola. Brasília, v. 13, n. 25, p. 137-153, jan./mai. 2019. Disponível em: <http://retratosdaescola.emnuvens.com.br/rde>. Acesso em 15 de abril de 2020.

ANFOPE. Manifesto da ANFOPE em defesa da democracia. 2020. Disponível em: http://www.anfope.org.br/wp-content/uploads/2020/03/1.-Manifesto-ANFOPE-emdefesa-da-educa\%C3\%A7\%C3\%A3o-e-da-democracia-01032020.pdf Acesso em 15 de abril de 2020.

AUSTRÁLIA. Australian Professional Standards for Teachers, 2018. Disponível em: https://formacaoprofessor.com/2019/11/27/cne-usa-referenciais-docentes-da-australiapara-bnc-da-formacao/ Acesso em 15 de abril de 2020. 
A Resolução CNE/CP N. 2/2019 e os retrocessos na formação de professores

BAZZO, Vera, SCHEIBE, Leda. De volta para o futuro... retrocessos na atual política de formação docente. In: Revista Retratos da Escola, Brasília, v. 13, n. 27, p. 669-684, set./dez. 2019. Disponível em: 〈http://retratosdaescola.emnuvens.com.br/rde>. Acesso em 15 de abril de 2020.

BRASIL. Resolução CNE/CP n. 1/2002 de 18 de fevereiro de 2002. Brasília, 2002. Disponível em: http://portal.mec.gov.br/cne/arquivos/pdf/rcp01_02.pdf. Acesso em 15 de abril de 2020.

BRASIL. Resolução CNE/CP n. 2, de 1 de julho de 2015. Brasília, 2015. Disponível em: http://www.portal.mec.gov.br/cne/arquivos/pdf/rcp01_06.pdf. Acesso em 15 de abril de 2020.

BRASIL. Parecer da Resolução CNE/CP n. 2, de 1 de julho de 2015. Brasília, 2015. Disponível em: http://portal.mec.gov.br/index.php?option=com_docman\&view=download\&alias $=1762$ 5-parecer-cne-cp-2-2015-aprovado-9-junho-2015\&category_slug=junho-2015pdf\&Itemid=30192 Acesso em 15 de abril de 2020.

BRASIL. Resolução CNE/CP n. 2, de 20 de dezembro de 2019. Brasília, 2019. Disponível em: http://portal.mec.gov.br/docman/dezembro-2019-pdf/135951-rcp002-19/file Acesso em 15 de abril de 2020.

BRASIL. Lei n. 13.005, de 25 de junho de 2014. Brasília, 2014.

DIAS, Rosanne Evangelista; LOPES, Alice Casemiro. Competências na formação de professores no Brasil: o que (não) há de novo. In: Educação \& Sociedade, Campinas, v. 24, n. 85, p. 1155-1177, dez. 2003.

DOURADO, L. F. Diretrizes Curriculares Nacionais para a Formação Inicial e Continuada dos Profissionais do Magistério da Educação Básica: Concepções e Desafios. In: Educação \& Sociedade, Campinas, v. 36, no. 131, p. 299-324, abr.-jun., 2015. Disponível em: http://www.scielo.br/pdf/es/v36n131/1678-4626-es-36-131-00299.pdf Acesso em 30 de abril de 2020.

CUNHA, Maria Isabel da. (org). Trajetórias e lugares de formação da docência universitária: da perspectiva individual ao espaço institucional. Araraquara, SP: Junqueira \& Marin, Brasília, DF: CAPES: CNPq, 2010.

FREITAS, Luiz Carlos. Os reformadores empresariais da educação: da desmoralização do magistério a destruição do sistema público de educação. Educação \& Sociedade, Campinas, v.33, n¹19, p.379-404, abr.-jun. 2012.

MAUÉS, O. As políticas de formação e a pedagogia das competências. In: REUNIÃO DA ANPED, 27, 2004, Caxambu. Sociedade democrática e educação: qual universidade? Caxambu, MG: ANPED, 2004. Disponível em: http://www.anped.org.br/ sites/default/files/t0516.pdf Acesso em: 20 de abril de 2020. 
MASSCHELEIN, Jan; SIMONS, Maarten. Em defesa da escola: uma questão pública. Belo Horizonte: Autêntica, 2013.

NOGUEIRA, Elizabeth Saramela. Políticas de formação de professores: a formação cindida (1995 - 2002). Tese de doutorado. Defendida no Programa de Pós-Graduação em Educação na UFRJ, 2003, 198 p. (mimeo).

SANTOS, Boaventura de Sousa. Da Ideia de Universidade à Universidade de Ideias. Revista Crítica de Ciências Sociais, n²7/28, junho 1989.

SILVA, Kátia Augusta Curado Pinheiro Cordeiro da. A (de) Formação de Professores na Base Nacional Comum Curricular. In: UCHOA, Antonio Marcos da Conceição; LIMA, Átila de Menezes; SENA, Ivânia Paula Freitas de Souza (Orgs.) Diálogos críticos, volume 2: reformas educacionais: avanço ou precarização da educação pública? [recurso eletrônico] / Antonio Marcos da Conceição Uchoa; Átila de Menezes Lima; Ivânia Paula Freitas de Souza Sena (Orgs.) -- Porto Alegre, RS: Editora Fi, 2020.

* Suzane da Rocha Vieira Gonçalves é professora do Programa de Pós-Graduação em Educação do Instituto de Educação da Universidade Federal do Rio Grande - FURG. Doutora em Educação Ambiental pela FURG e Mestre em Educação pela UFSC, é Vice-diretora do Instituto de Educação (2013-2020) e Líder do Grupo de Pesquisa Educação, Trabalho e Docência. É primeira secretária da Diretoria Executiva nacional da ANFOPE (2018-2020).

E-mail: suzanevieira@gmail.com

https://orcid.org/0000-0002-3156-2693

** Maria Renata Alonso Mota é professora do Programa de Pós-Graduação em Educação do Instituto de Educação da Universidade Federal do Rio Grande - FURG. Doutora em Educação pela UFRGS e Mestre em Educação pela UFPE. Atualmente é Diretora do Instituto de Educação da FURG (2013-2020) e presidente do FORUMDIR.

e-mail: mariarenata.alonso@gmail.com

https://orcid.org/0000-0003-1057-9426

*** Simone Barreto Anadon é professora do Instituto de Educação da Universidade Federal do Rio Grande - FURG. Doutora e Mestre em Educação pela UFPE, é Diretora Pedagógica da Pró-Reitoria de Graduação da FURG (2016-2020).

E-mail: simoneanadon74@gmail.com

https://orcid.org/0000-0002-9451-2167 